\title{
Physician-Patient Interaction for Smoking Cessation Medications: A Dance of Mutual Accommodation?
}

\author{
Leif I. Solberg, MD, Chris J. Enstad, BS, Raymond G. Boyle, PhD, and \\ Winnie W. Nelson, PharmD, MS
}

Objective: To study physician-smoker interactions around the receipt of smoking cessation medication prescriptions to better understand the low rates of reported assistance and follow-up.

Methods: A stratified random sample of smokers recently filling prescriptions for cessation medications was identified for a phone interview about the quitting experience. The transcriptions of those portions of 50 interviews that addressed cessation contacts with clinicians were reviewed by the coauthors and analyzed for quantifiable data, observations, and themes.

Results: Although there were low levels of reported physician adherence to the Assist and Arrange recommendations of the Public Health Service 5As clinical guideline for smoking cessation, 27 (55\%) of these smokers were quit at 1 to 3 months after the medication fill. Smoker descriptions of the contacts with their physicians about smoking cessation suggested nonconfrontational, collaborative, and satisfying interactions that were flexibly dominated by either party. Physician assistance predominantly concerned use of the medication (66\%).

Conclusions: These physician-smoker interactions seemed to be mutually accommodative. Given the apparent high quit rates and limited evidence of smoker interest in other forms of assistance, perhaps a physician-dominant encounter is not as common or as necessary as has been thought. ( $\mathrm{J}$ Am Board Fam Med 2006;19:251-7.)

Despite the evidence from numerous randomized clinical trials that physician advice and assistance are effective in facilitating smoking cessation by their patients, those actions have been less frequent than tobacco control experts believe to be necessary. ${ }^{1-5}$ For example, HEDIS (health plan employer data and information set) rates in Minnesota health plans for smokers being asked about smoking and advised to quit are above the national average. ${ }^{6}$ Nevertheless, we found that of those smokers reporting interest in quitting at the time of their last clinic visit, only $37 \%$ reported receiving encouragement to use medications, $27 \%$ were given a prescription for such, and $10 \%$ reported that any type of follow-up was arranged, although each of these actions is recommended in the national guideline. ${ }^{5}$

Submitted 1 August 2005; revised 13 October 2005; accepted 17 October 2005.

From HealthPartners Research Foundation, Minneapolis, MN.

Funding: Supported by Grant 044163 from The Robert Wood Johnson Foundation, Addressing Tobacco in Managed Care Program.

Conflict of interest: none declared.

Corresponding author: Leif I. Solberg, MD, HealthPartners Research Foundation, PO Box 1524, MS\#21111R, Minneapolis, MN 55440 (E-mail: leif.i.solberg@healthpartners.com).
Smokers who have both received and filled a prescription for a smoking cessation medication would seem to be a particularly interesting group to help us to understand these types of patient-physician interactions. These smokers have demonstrated their quit interest through actually filling the prescription, and it would seem particularly important to provide them with information, assistance, and follow-up.

Recently, we reported on a survey of smokers soon after they had filled a physician's prescription for cessation medications. ${ }^{7}$ Like the smokers described above, they reported low rates of assistance and follow-up arrangements, except that two-thirds of them did report being told how to use the medication and being given written instructions about the medications. However, the only reported physician action statistically associated with the patient's use of the medication was requesting the patient to set a quit date, and no action was significantly associated with cessation among the 30\% who had quit at 3 months.

These findings are puzzling, raising questions about some of the recommendations in the US Public Health Service's Clinical Practice Guideline for Treating Tobacco Use and Dependence. ${ }^{8}$ 
Therefore, we interviewed a random sample of such smokers to learn more about the circumstances under which they had received their prescription. Specifically, we wanted to learn whether there were important contextual issues such as who initiated the topics of quitting and medication use and how discussions of assistance and follow-up occurred. Such information might help us to understand why physician support seems so limited and ineffectual for these smokers who were in the preparation phase of quitting. ${ }^{9}$ We hoped that any themes or hypotheses generated from this information could guide further research, while also assisting organizations and clinicians to improve their effectiveness in this important area of health care.

\section{Methods}

All the smokers in this study and in the associated survey study were members of HealthPartners health plan, living primarily in the Minneapolis-St. Paul metropolitan area of Minnesota. Approximately one-third of such members receive their care through a staff model medical group owned by the health plan, and the rest do so through approximately 45 other private medical groups with health plan contracts. In 1998, HealthPartners introduced health insurance coverage for cessation medications as long as a physician prescribed them, but there was no requirement or coverage for cessation counseling.

As described in more detail in other articles, health plan members who had filled a prescription for a covered cessation medication were randomly selected for a mailed survey. The sample was stratified to include equal proportions of subjects with and without chronic medical conditions related to smoking. ${ }^{7,10}$ Of the eligible smokers who were not selected to receive the mail survey, 112 were randomly selected for recruitment for this telephone interview, in hopes that at least 50 of them would agree to participate. A letter describing the phone interview and providing a mechanism to opt out was sent to these 112 potential subjects approximately 3 weeks after the members had filled a smoking cessation medication prescription. Ten days after the mailing, an experienced smoking cessation counselor-interviewer (CE) attempted to contact them to complete phone interviews, making up to 8 call attempts at various times and days. The interviewer used a scripted question set that was revised after pilot testing with 9 smokers from the same pool of eligible smokers. The interviews averaged 20 minutes in length, were tape recorded directly from the phone line, and were transcribed verbatim by a vendor.

The portion of the interview addressing the interactions about smoking cessation with the physician and health care system included the following topic areas with semistructured questions about the encounter at which subjects received their prescription $^{11}$ :

\section{Reason(s) for the encounter}

2. How cessation and the medication were brought up and who did so

3. Reason(s) for and who made the medication choice

4. Information or advice from the physician

5. Follow-up plans and actions

Subjects were also asked about any subsequent cessation contacts with the physicians and whether they had used the medicine, made quit attempts, and were quit at the time of the interview.

Key quantifiable data describing the subjects, their quit behaviors, and the topics identified above were summarized for the 50 subjects who completed the phone interview. One author reviewed all 424 pages of transcripts, both to select the 148 pages that related in any way to the medical care encounters and to summarize other relevant quantifiable information. All authors independently read and reread those 148 pages (for major observations and then met as a group to list them in a round robin fashion and to clarify or combine them, constantly comparing these interpretations against the data and in relation to the context. In this way, analytic categories and, eventually, hypotheses were derived from the data (grounded theory) rather than a priori. ${ }^{12} \mathrm{We}$ then discussed these ideas and gradually, in a series of meetings, developed a consensus on the most important observations and hypotheses or themes that we generated from these interviews after reaching saturation. Group review of individual transcripts that exemplified or contradicted each observation or hypothesis were a central part of this process. ${ }^{13}$ Finally, brief representative excerpts were selected for this article. The perspectives of the co-author investigators were those of a family physician (LS), health behavior change counselor (CE), smoking cessation 
Table 1. Summary Data on Smoker Interviewees $(n=49)$

\begin{tabular}{|c|c|c|}
\hline Variables & $\mathrm{N}$ & Percentage \\
\hline \multicolumn{3}{|l|}{ Age group } \\
\hline 20 to 39 & 13 & 26 \\
\hline 40 to 59 & 31 & 63 \\
\hline 60 to 79 & 5 & 10 \\
\hline Male & 20 & 41 \\
\hline Years of smoking-mean (SD) & & 26.6 years $(13.1)$ \\
\hline Smoking-related chronic condition* & 31 & 63 \\
\hline $\begin{array}{l}\text { Health concerns were main reason for wanting } \\
\text { to quit }\end{array}$ & 35 & 71 \\
\hline \multicolumn{3}{|l|}{ Medication prescribed: } \\
\hline Bupropion & 34 & 69 \\
\hline NRT patch & 9 & 18 \\
\hline NRT inhaler & 5 & 10 \\
\hline NRT spray & 1 & 2 \\
\hline \multicolumn{3}{|l|}{ Prior use of cessation medication: } \\
\hline Bupropion & 17 & 35 \\
\hline NRT & 32 & 65 \\
\hline Used the medication & 44 & 90 \\
\hline Made a 24-hour quit attempt & 36 (1 without medication use) & 73 \\
\hline Reported being quit at time of interview & 27 (18, bupropion; 7, patch; 2, inhaler) & 55 \\
\hline
\end{tabular}

* Hypertension, cardiovascular disease, respiratory disease, hyperlipidemia, or diabetes.

researcher (RB), and pharmacist (WN). This study was approved by the HealthPartners Institutional Review Board.

\section{Results}

Of the potential 112 subjects identified, 16 had no correct telephone number. Thirty-three could not be reached after 8 attempts, 13 refused to participate, and 50 completed the interview, resulting in an adjusted response rate of $79.4 \%$ of those reached. However, one of those 50 had quit smoking 2.5 years before and made this physician visit for help in breaking her addiction to nicotine gum, leaving 49 smokers for analysis. The interviews took place an average of 53 days after they had filled their prescriptions.

Table 1 provides key descriptive data on the 49 completed smoking interviewees and their cessation actions. Most were middle-aged, had at least one chronic condition, and health concerns were their main reason for wanting to quit. Half reported being quit at the time of the interview for at least 7 days, and $60 \%$ of these had been quit for at least 24 days.

The smoker-reported features of the interaction between the smoker and physician as perceived by the authors are summarized in Table 2. In the majority of cases, the smokers reported that they had initiated the smoking cessation discussion as well as the idea of using medication, and reported being responsible for the choice of medication. As was the case with the larger mailed survey of such smokers, less than one-third reported that the physician had discussed any assistance beyond information about using the medication or had recommended any follow-up. ${ }^{7}$

Although the interviews suggested that patients dominated half of the cessation interactions, neither this nor the physician-dominant interactions seemed to be associated with any greater degree of success in quitting. However, where there was an equal balance in the interaction, 5 of 6 had quit. Of those with a chronic smoking-related condition, the three-fourths who gave health concerns as their main reason for quitting were twice as likely to have quit as those who gave other reasons. However, the reason for quitting had no relationship to quit success for those without these chronic conditions. Where the gender of the physician could be identified in the interview notes (all but 3 cases), male physician encounters were somewhat more likely to be associated with patients quitting, just as male smokers had a somewhat greater quit rate. 


\begin{tabular}{lcc}
\hline Variables & N & Percentage \\
\hline Appointment made to discuss smoking cessation & 11 & 22 \\
Patient initiated the smoking cessation discussion & 30 & 61 \\
Using medication was patient's idea & 33 & 67 \\
Choice of medication was patient's & 28 & 57 \\
MD assistance: & 33 & 67 \\
$\quad$ Discussed medication (14/19 where MD initiated discussion) & 15 & 31 \\
Discussed using phone counseling & 12 & 24 \\
Discussed ideas for quitting & 14 & 29 \\
MD requested follow-up appointment (5/19 MD initiated discussion) & 12 & 24 \\
Patient did or will attend follow-up appointment & & \\
Who dominated the encounter: & 25 & 51 \\
Patient & 18 & 37 \\
Physician & 6 & 61 \\
Neither & 30 & \\
Physician was male (3 unknown) & & \\
\hline
\end{tabular}

Review and discussion of the interviews led the authors to make the following observations:

1. Very few prescriptions originated from phone interactions, even though these subjects were obviously comfortable with phone interviews and their physicians.

2. All the prescribers were physicians (no nurse practitioners or dentists) and few were subspecialists, despite most smokers having chronic medical conditions that might lead to specialty encounters.

3. The smoker's motivation for the medication usually came either from external sources (eg, friends, internet, direct-to-consumer ads) or from previous personal experience with particular medications.

- No. 17. "Oh, it was definitely my idea. I guess from other people who have tried, people that maybe had the most success."

- No. 81. "I research everything before I asked [my doctor] for anything. I go on the internet and get to looking up things."

- No. 87. "I heard from a couple of guys at work that had quit that that was the best thing."

4. Thirty-seven smokers reported a long history of smoking, with multiple prior quit attempts and often with prior medication use and 29 reported a long pattern of cessation discussions with their physicians.
- No. 10. "Well they ask you every time you are in there, you know-Are you interested?"

- No. 17. "She has brought it up more than once."

- No. 40. "It was my yearly physical and my doctor and I have discussed smoking for several years and she knows that I have tried a couple of other times."

- No. 119. "I had actually tried almost everything else in previous years to that, and nothing had ever worked for me."

5. Although many smokers seemed to have strong interest in help with quitting, this was nearly entirely limited to medications, with only 4 patients reporting much interest in other resources like counseling.

- No. 22. "They gave me a telephone number that I could call... and I thought, nah, I don't need that."

- No. 91. "She might have brought it up [telephone counseling], but I would never do something like that."

6. This focus was matched by the physicians, whose principal comments in 41 of the cases seemed to be on medication selection and information about its use.

- No. 40. "She just told me how I have to take it - - - she didn't really say much else."

- No. 2. "He just gave me the inhaler and he didn't talk about anything else. I just wanted something right away." 
7. Physicians did seem to have mentioned external resources (especially phone counseling) in 29 of the cases, but didn't actively promote it and only one quarter suggested follow-up for smoking cessation.

- No. 40. "Were you asked to have a followup[?]" "No, but as a matter of fact I have seen her since then and I told her what my target date was and she wished me good luck and that was about it."

8. There was rarely any confrontation. When physicians seemed to prefer a particular medication or suggested follow-up, smokers seemed quite willing to comply. On the other hand, physicians usually seemed to be willing to go along with any strong smoker interests in the approach to quitting or medication selection.

- No. 5. "I was very clear of what I wanted. I said, you know here is my plan, here is what I want to do, here is the help I need. What I am really coming in here for is to get the prescription for the Zyban. ... so he agreed and, again, based on my past history of it helping, you know, we just kind of said, yup let's go ahead with it."

- No. 9. "The doctor didn't talk about how to use it [Zyban] because I had already told her that I had learned about it and what it did and how to use it."

9. Smokers nearly always seem to have been satisfied with the physician encounter, even to the point of covering for behavior they didn't recall very well.

- No. 93. In response to “... did he give you some tips, etc": "Well, I can't really remember positively. He probably did - - -we may have just skipped over that because I already knew."

- No. 43. "I was really satisfied with the way he handled the whole thing. I would rather a doctor not hand you and say, you know, hey you're gonna die - - - people have to make up their own mind that they're going to do that when they are ready to do it."

10. There was rarely description of a comprehensive plan for quitting over time-just the next step or 2.

Only 7 of the interviewees could be said to represent disconfirming cases for the above descriptions, and these occurred with specialists or while hospitalized

\section{Discussion}

These interviews help us to better understand the previous survey findings suggesting incomplete physician adherence to the 5 As recommended by the national clinical guideline for smoking cessation. One reason for these findings seems to be that these specific encounters at which cessation medications were prescribed are often not isolated events for either patient or physician. Rather, they are simply another step in a long chain of cessation experiences for the smoker as well as for the smoker-physician interaction. Thus, scrutiny of a particular visit is a bit like reading a random page or chapter in a book, while disregarding what preceded it.

These interviews also suggest that, like many other doctor-patient interactions, discussions about quitting smoking vary greatly as to which party takes the lead-and when one party has strong ideas, the other party often acquiesces. Moreover, there often seems to be a mutual recognition that the patient's motivation and self-actions are critical to the solution of this particular problem. Where patients have experiences and ideas about what they want to do, the physician usually seems to go along. These physicians seem to have capitalized on their long-term relationship with their patients, on relevant acute or chronic conditions, and on any other opportunities that surfaced to advise often. They kept the door open for the day when their patients were ready to quit.

Finally, these interviews suggest that it is not just the physician who seems uninterested in arranging cessation counseling and follow-up-most of these smoking patients are at least as uninterested. Thus, the physician focus on medications and not those other actions recommended in guidelines might reflect their learned understanding of and deferral to patient preferences.

Therefore, what initially seemed to be a lack of physician adherence to guidelines may instead reflect the different reality that they experience daily in their practices. Their approach seemed to work relatively well in this subset of smokers, as reflected by the $90 \%$ smoker use of the medications they filled and the $55 \%$ quit rate. 
Consideration of these observations led us to generate the following 4 themes or hypotheses for broader consideration and future studies:

1. These encounters were often just the next step in a long history of personal cessation consideration and experience by the smokers and of cessation interactions with their physician.

2. These smoker-physician encounters resembled an ongoing friendly dance between the 2 participants more than the physician-dominant single encounter model suggested by the national guideline and tested in the published controlled trials.

3. The main focus of the dance was around medications on the part of both the smoker and physician. Although information and other resources were usually mentioned, neither party seemed to be strongly interested in them.

4. It was usually the case that neither physicians nor patients seemed to see much need for follow-up specifically for smoking cessation, probably assuming that it would be mentioned in future encounters or if the patient felt some more help was needed.

Long before the Institute of Medicine's report, Crossing the Quality Chasm, called for attention to 6 aims that included patient-centeredness, there had been many published articles and studies highlighting this same issue. ${ }^{14}$ The Emanuels characterized the period since 1970 as "a struggle over the patient's role in medical decision making that is often characterized as a conflict between autonomy and health, between the values of the patient, and the values of the physician."15 The usual assumption has been that what they call the "paternalistic model" has been and continues to be the dominant approach used by physicians. Laine and Davidoff describe an evolution from a historical physiciancentered care model to one where "physicians have begun to incorporate patients' perspectives in ways that increasingly matter," ie, to patient-centered medicine. $^{16}$

We propose that the interviews reported on in this study suggest that, at least insofar as the important medical role in smoking cessation is concerned, patient-centeredness has become a fairly common reality. We found very little evidence in these 49 interviews, representing encounters with an equal number of different physicians, of physi- cian authoritarianism. Even in the minority of encounters perceived as physician dominant, the patient-reported interaction seemed to be largely respectful and satisfying.

Such a conclusion, if reinforced by other studies, raises some questions about the approach usually taken by tobacco control advocates and illustrated by the language and recommendations in the US Public Health Service clinical practice guideline, Treating Tobacco Use and Dependence. ${ }^{8}$ For example, the second " $\mathrm{A}$ " of the $5 \mathrm{~A}$ recommendations is Advise to Quit-"In a clear, strong and personalized manner urge every tobacco user to quit." Only after this step is it recommended to Assess the "patient's willingness to quit at this time." Such a sequence is not very patient-centered or compatible with the relationship described in these interviews. Similarly, physicians are told under the last "A" of Arrange to "schedule follow-up contact," not to recommend it or to ask patients about their willingness to have a return visit or call. There is no discussion about the situation described often in these interviews where a patient brings up the issue of quitting or asks for specific help. There is also no recognition of the pattern very frequently described by these patients of recurrent discussions between them and their doctors about smoking cessation over long periods of time.

We do recognize the limitations of this study. By focusing only on smokers who have filled a prescription for smoking cessation medications, we have selected a potentially atypical minority of smokers. In addition, these interviews only represent the story of the encounter from one point of view, the smoking patient's, and only 49 of those. Finally, as a qualitative study, there is always the risk that the authors have not objectively and fully analyzed the material. The transcripts we reviewed seemed so consistently supportive of the observations we describe above; however, this seems unlikely. Many articles and books have addressed the quality challenges for qualitative research. ${ }^{17,18}$ However, they also highlight the importance of qualitative research in helping us to improve our understanding of medicine and medical care.

Therefore, we think that the observations described above need and deserve thoughtful reaction and further studies. One message for clinicians is that when a patient requests or accepts a prescription for smoking cessation medications and fills it, that patient is highly likely to quit smoking, so they 
should not resist using these medications freely. The 4 tentative hypotheses do raise questions about the way that the physician's role in smoking cessation has been approached so far in most of the research studies and recommendations. Perhaps some studies should be conducted that take a longitudinal view of that role. Moreover, at least for this preventive service, perhaps physician-patient relationships are not as unidirectional and authoritarian as they are still usually described.

\section{References}

1. Fiore MC, Bailey WC, Cohen SJ, et al. Treating tobacco use and dependence. Clinical practice guideline. Rockville (MD): US Department of Health and Human Services. Public Health Service. 2000. AHRQ publication no. 00-0032.

2. Ellerbeck EF, Ahluwalia JS, Jolicoeur DG, Gladden J, Mosier MC. Direct observation of smoking cessation activities in primary care practice. J Fam Pract 2001;50:688-93.

3. Sesney JW, Kreher NE, Hickner JM, Webb S. Smoking cessation interventions in rural family practices: an UPRNet study. J Fam Pract 1997;44: $578-85$.

4. Thorndike AN, Rigotti NA, Stafford RS, Singer DE. National patterns in the treatment of smokers by physicians. JAMA 1998;279:604-8.

5. Solberg LI, Davidson G, Alesci N, Boyle RG, Magnan S. Physician smoking-cessation actions: are they dependent on insurance coverage or on patients? Am J Prev Med 2002;23:160-5.

6. National Committee for Quality Assurance (NCQA). Quality Compass 2004: the most comprehensive database of health plan performance data anywhere. Available from: http://www.ncqa.org. Accessed January 18, 2005.
7. Solberg LI, Asche SE, Boyle RG, Boucher JL, Pronk NK. Frequency of physician-directed assistance for smoking cessation in patients receiving cessation medications. Arch Intern Med 2005;165:656-60.

8. Fiore MC, Bailey WC, Cohen SJ, et al. A clinical practice guideline for treating tobacco use and dependence: a U.S. Public Health Service report. The Tobacco Use and Dependence Clinical Practice Guideline Panel Staff and Consortium Representatives. Rockville (MD): U.S. Department of Health and Human Services. Public Health Service. 2000.

9. Prochaska JO, Velicer WF. The transtheoretical model of health behavior change. Am J Health Promot 1997;12:38-48.

10. Boyle RG, Solberg LI, Asche SE, Boucher JL, Pronk NP, Jensen CJ. Offering telephone counseling to smokers using pharmacotherapy. Nicotine Tob Res 2005;7(Suppl 1):S19-S27.

11. Britten N. Qualitative interviews in medical research. Br Med J 1995;311:251-3.

12. Strauss A, Corbin J. Grounded theory methodology: an overview. In: Denzin NK, Lincoln YS, editors. Handbook of qualitative research. Thousand Oaks (CA): Sage Publications; 1994. p. 273-8.

13. Pope C, Ziebland S, Mays N. Qualitative research in health care. Analysing qualitative data. BMJ 2000; 320:114-6.

14. Institute of Medicine. Crossing the quality chasm: a new health system for the 21 st century. Washington (DC): National Academy Press; 2001.

15. Emanuel EJ, Emanuel LL. Four models of the physician-patient relationship. JAMA 1992;267:2221-6.

16. Laine C, Davidoff F. Patient-centered medicine. A professional evolution. JAMA 1996;275:152-6.

17. Mays N, Pope C. Qualitative research in health care. Assessing quality in qualitative research. BMJ 2000; 320:50-2.

18. Malterud K. Qualitative research: standards, challenges, and guidelines. Lancet 2001;358:483-8. 